\title{
Análise do espaço urbana no entorno da Ponte Estaiada, Teresina, Piauí através do uso de imagens do Google Earth.
}

\author{
Analysis of Urban Space surrounding the Ponte Estaiada bridge, Teresina, Piauí through the \\ use of Google Earth images.
}

\author{
Melo $^{1}$, J. C.; Sousa ${ }^{1}$, R. S. de; Moraes ${ }^{2}$, M. V. A. R. \\ jadersoncmelo@gmail.com;
}

\begin{abstract}
Resumo
O artigo apresenta características do processo de urbanização da cidade de Teresina-PI, principalmente no entorno da Ponte Mestre João Isidoro França, conhecida como Ponte Estaiada. O objetivo foi analisar a produção do espaço urbano, como resultado da configuração de processos que refletem na atuação dos agentes produtores do espaço, bem como a atuação das diversas atividades cotidianas da sociedade, que acabam por ser refletida na infraestrutura da cidade e na reorganização ou reestruturação desse espaço no decorrer do tempo, promovendo dinâmicas socioespaciais e mudanças na paisagem. Foi realizada uma análise multitemporal através das imagens do Google Earth (2005 e 2015), além de análise bibliográfica e documental. Nesse sentido observou-se o desenvolvimento paralelo da cidade sem o devido planejamento urbano e com modificações na paisagem, que podem ser facilmente identificadas na análise das imagens de satélites. Constatou-se que o espaço urbano está em constante mudança, seja ele planejado ou não, como foi observado na análise espacial das imagens do Google Earth.
\end{abstract}

Palavras-chave: Planejamento urbano. Mudanças na paisagem urbana. Google Earth.

\begin{abstract}
The paper describes the process of urbanization of the city of Teresina, Piauí, mainly surrounding the Bridge named Mestre João Isidoro França, known as Ponte Estaiada. The objective was to analyze the production of urban space as a result of configuration processes that reflect the performance of the producers of the space agents and the activities of the various daily activities of society, which turn out to be reflected in the city's infrastructure and the reorganization or restructuring that space over time, promoting socio-spatial dynamics and changes in the landscape. One multi-temporal analysis using Google Earth images (2005 and 2015) was carried out, as well as bibliographic and documentary analysis. In this sense there was the parallel development of the city without proper urban planning and changes in the landscape, which can be easily identified on the satellite image analysis. It was found that the urban space is constantly changing, whether planned or not, as was observed in the spatial analysis of Google Earth images.
\end{abstract}

Keywords: Urban Planning. Changes in Urban Landscape. Google Earth

\section{INTRODUÇÃO}

O espaço urbano é resultado de um processo de interação entre as dinâmicas populacionais, das atividades econômicas e culturais e dos agentes espaciais urbanos. Os agentes produtores das cidades como os proprietários fundiários, proprietários dos meios de produção, agentes imobiliários, o Estado e os grupos sociais excluídos criam estratégias que variam no tempo e no espaço reproduzindo diferentes paisagens urbanas, normalmente associadas ao aspecto econômico, social e cultural local, reproduzindo assim, um espaço dinâmico e multável.

Nesse sentido há cidades que passam por um processo de evolução, se originando a partir de um ponto de parada de uma rota comercial, formando posteriormente um aglomerado urbano, 
depois uma vila, uma cidade e até mesmo uma capital, mas também há cidades que não passam por esse processo de evolução, já são criadas pelo Estado para atender determinadas funções como no caso de Teresina - PI e Brasília - DF, criadas com funções administrativas, porém podem se dinamizarem ao longo do tempo tanto nos aspectos econômicos como sociais.

Portanto, não há como definir a origem de uma cidade, baseado apenas em um agente, com exceção do agente Estado que possui o poder de criar uma cidade e dos agentes imobiliários que estão presentes no início do processo de formação de toda e qualquer cidade. No entanto, o desenvolvimento da mesma é promovido pelos demais agentes, que passam a atuar no processo de desenvolvimento econômico, social e cultural das cidades ao longo do tempo, como ocorreu em Teresina, que é criada com uma função administrativa, mas adquire outras de destaque, como a atividade comercial que se tornou a base econômica da capital por influência não somente dos agentes espaciais urbanos como também da própria sociedade.

Nessa perspectiva do mundo capitalista, o homem também está sempre produzindo e reproduzindo o espaço, existindo sempre uma contribuição socioespacial da sociedade. Nesse mesmo sentido ocorre o desenvolvimento de Teresina, que inicialmente segue um planejamento urbano e posteriormente o desenvolvimento do espaço urbano continua a ocorrer com a ocupação das diversas áreas, sem necessariamente seguir um planejamento de ordenamento dessa ocupação, levando a futuras obras de intervenção e reestruturação urbana da cidade, muitas vezes destruindo áreas ambientais e antigos espaços para (re)construir novos, na tentativa de readaptação do espaço a necessidade urbana da cidade, como ocorre no entorno da Ponte Estaiada, gerando mudanças espaciais no entorno dessa obra.

Este artigo, inicialmente, destacará um breve histórico da expansão da cidade de TeresinaPI, com a criação de suas pontes, dado ênfase a Ponte Mestre João Isidoro França. Tendo como objetivo geral a análise do entorno desta ponte com os recursos que as Geotecnologias nos proporcionam. E como objetivo específico a análise dos dois lados da ponte: centro/norte (Bairro Morro da Esperança) e leste (Bairro de Fátima), mostrando as modificações através das imagens do Google Earth e fotografias atuais, fazendo uma análise de seus contrastes sociais.

\section{BREVE HISTÓRICO DA EXPANSÃO DE TERESINA, PIAUÍ}

Teresina tem uma origem peculiar, pois, dentre todas as cidades brasileiras, foi a primeira a ter o espaço que viria a se constituir em seu núcleo urbano, escolhido para ser cidade. E o que é mais importante: Teresina foi projetada para ser uma cidade-capital (ABREU; LIMA, 2000). 
A partir de 1852, a forte presença da natureza faz-se notar em princípio pelo local escolhido para construir a nova sede urbana do município da Vila do Poti, que se tornaria a nova capital do Piauí. O conselheiro Saraiva, então Presidente da Província do Piauí, escolheu um lugar à margem direita do rio Parnaíba, no planalto entre as últimas curvas dos rios Parnaíba e Poti, antes do encontro desses dois rios, pois, rio abaixo, o Poti desenha sua barra ao jogar suas águas no rio Parnaíba. (LIMA, 2002).

A nova capital do Piauí foi projetada por Conselheiro Saraiva, tendo como traçado geométrico a forma de tabuleiro de xadrez (Figura 01), a primeira do Brasil com esta configuração, e que determinou o crescimento radiocêntrico da cidade de Teresina. $\mathrm{O}$ centro era representado pela Igreja Nossa Senhora do Amparo, a primeira edificação da cidade. De norte a sul, Teresina tinha 3 km e 18 quadras, e, de leste a oeste, os limites da cidade eram os rios Poti e Parnaíba, com 12 quadras, totalizando uma área de $43 \mathrm{~km}^{2}$ (VIANA, 2005).

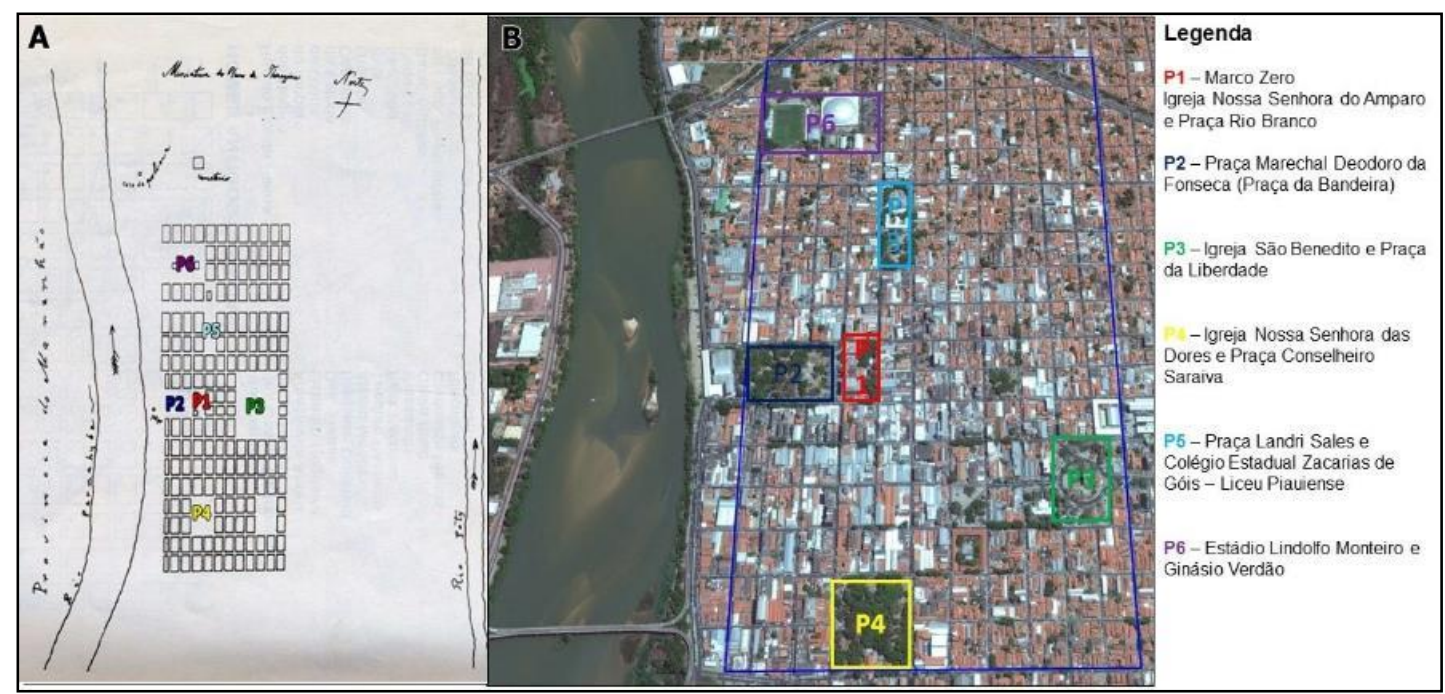

Figura 01. A) Plano inicial 1855; B) Teresina 2015. Fonte: A) Tollstadius (2013); B) Google Earth (2015). Adaptado pelos autores.

A Figura 1A apresenta exatamente o que Viana (2005) afirmou sobre o plano inicial da cidade de Teresina em formado de um tabuleiro de xadrez, já a Figura 1B nos mostra a situação atual da cidade, onde conseguimos observar a expansão da cidade e identificar seis pontos criados em sua formação inicial que ainda estão presentes da paisagem atual da cidade.

Até a primeira década do século XX, o perímetro urbano de Teresina não alcançava o Alto da Jurubeba, região onde foi edificada a Igreja São Benedito entre 1874 e 1886. Tudo fora dessa área urbanizada era repleto de mata fechada, casebres de palha, e cercas que demarcavam algumas localidades rurais: as chácaras. A antiga Estrada Real (Avenida Frei Serafim), por exemplo, encontrava-se cheia de terrenos cercados até as proximidades do Rio Poti. Chegava-se a eles por meio de veredas de 'carroçal', estradas de terra (TERESINA ANTIGA, 2015). 
Nos primeiros momentos da ocupação da cidade de Teresina, previa-se um crescimento que seguia a direção oeste/leste, na área compreendida entre os rios Parnaíba e Poti. Por ser o principal centro urbano do Estado do Piauí, desenvolveu-se na cidade a concentração das principais atividades econômicas, ligadas ao comércio e serviços (FAÇANHA, 1998).

A ocupação da margem direita do rio Poti se fortaleceu a partir da construção da ponte de concreto armado, que ligou a avenida Frei Serafim à rodovia BR-343, concluída em 1957, denominada de Ponte Juscelino Kubitschek. Anteriormente havia uma ponte estruturada em madeira, construída no ano de 1936, que, segundo consta na mensagem do governador Leônidas Mello à Assembleia Legislativa, no ano de 1936, "tinha um comprimento de 170,00m de extensão e uma largura de 6,20m.”. Essa ponte fazia a travessia do rio Poti, na altura do bairro Cristo Rei, antigo lugar São Raimundo, onde atualmente existe a ponte ferroviária e a ponte Wall Ferraz. Segundo Lima et Portela (2003), essa ponte de madeira foi destruída por uma enchente do rio Poti ainda na década de 1940, ficando a travessia do rio prejudicada. Em consequência da ruína da ponte, ainda segundo Lima et Portela (2003), a travessia passou a ser feita por balsa, no local conhecido por Porto dos Noivos, fazendo a interligação entre a avenida Frei Serafim e a avenida João XXIII. Essa situação perdurou até o ano de 1957, com a inauguração da ponte Juscelino Kubitschek. (CASTELO BRANCO, 2012, p. 90). Afirma Leal Junior (2014, p.78) que:

A expansão urbana de Teresina pode ser simplificada na Figura 2, em que são expostos os vetores de expansão da cidade até os dias atuais. Inicialmente concentrada na área do Centro, o processo de expansão da mancha urbana da capital está literalmente ligado à construção da cidade. Em todos os momentos relatados até aqui a instalação de algum elemento físico marca o início do deslocamento da população. Acompanhando a mesma figura poder-se-ia resumir tais relações da seguinte forma: a) $1^{\circ}$ momento: Execução do Plano Saraiva juntamente com a construção do traçado inicial e principais edifícios públicos, ocupação do que hoje chamamos de Centro Histórico. (Década de 1850); b) $2^{\circ}$ momento: Urbanização da Avenida Frei Serafim e consolidação da ocupação da mesma por pessoas de alta renda. Assim como o crescimento da "periferia do Centro" (Década de 1930); c) $3^{\circ}$ momento: A cidade começa a crescer para Norte e Sul dentro dos limites do Rio Parnaíba e Poti (Década de 1950); d) $4^{\circ}$ momento: Após a construção da Ponte Juscelino Kubitschek sobre o Rio Poti e a instalação do Hipódromo na outra margem do Rio, há um deslocamento das pessoas de alta renda para esta zona. Em paralelo a política habitacional do governo federal, cria conjuntos populares na zona Sul, distante do Bairro Centro (Década de1960); e) $5^{\circ}$ momento: após a construção da Ponte Mariano Gasoso sobre o Rio Poti, na zona Norte da cidade, houve um crescimento populacional significativo dos bairros localizados além rio, bairros de baixa renda (Década de 1980).

A Figura 2A nos mostra os cinco momentos e direção da expansão da cidade de Teresina de acordo com o que Leal Junior (2014) afirma, já a Figura 2B exibe a configuração atual da cidade marcando seu ponto inicial de formação e as partes de expansão. Ainda no âmbito da expansão de Teresina, Bueno (2015) destaca que:

(...) para a expansão da ocupação urbana, fluidez no tráfego de veículos e reestruturação da cidade, destaca-se a construção de pontes em Teresina, a qual possui dez construções desse porte: Ponte João Luís Ferreira - 1939 (Ponte Metálica) - conecta a Av. Miguel Rosa (Teresina) à Av. Teresina (Timon); Ponte Juscelino Kubitschek - 1957 (Ponte da Frei 
Serafim) - faz a ligação da Avenida João XXIII (Zona Leste) à Avenida Frei Serafim (Centro da Cidade); Ponte Engenheiro Antônio Noronha - 1972 (Ponte Nova) interliga Teresina pelo Bairro Tabuleta à Cidade de Timon (zona Sul); Ponte Deputado Paulo Ferraz (1977) - liga o Bairro Tancredo Neves (zona Sudeste) à Rodoviária de Teresina (zona Sul); Ponte Ministro Petrônio Portella - 1979 (Ponte da Primavera) interliga a Avenida Petrônio Portela (Zona Norte) à Avenida Universitária (Zona Leste); Ponte Antônio Mariano Castelo Branco - 1992 (Ponte do Poty Velho) - conecta o Bairro Poty Velho à Santa Maria da Codipi (zona Norte); Ponte Wall Ferraz (1995) - liga a Av. Higino Cunha (Zona Sul) à Av. Cajuína (Zona Leste); Ponte José Sarney - 1997 (Ponte da Amizade) - liga a Av. Maranhão (Teresina) à Av. Piaú (Timon); Ponte Estaiada Mestre João Isidoro França (2010) - liga a Av. Rio Poty (Zona Leste) à Av. Alameda Parnaíba (Zona Norte); Ponte Leonel Brizola - 2011 (Ponte do Mocambinho) - liga o Bairro de Mocambinho (zona Norte) ao Bairro Pedra Mole (zona Leste).

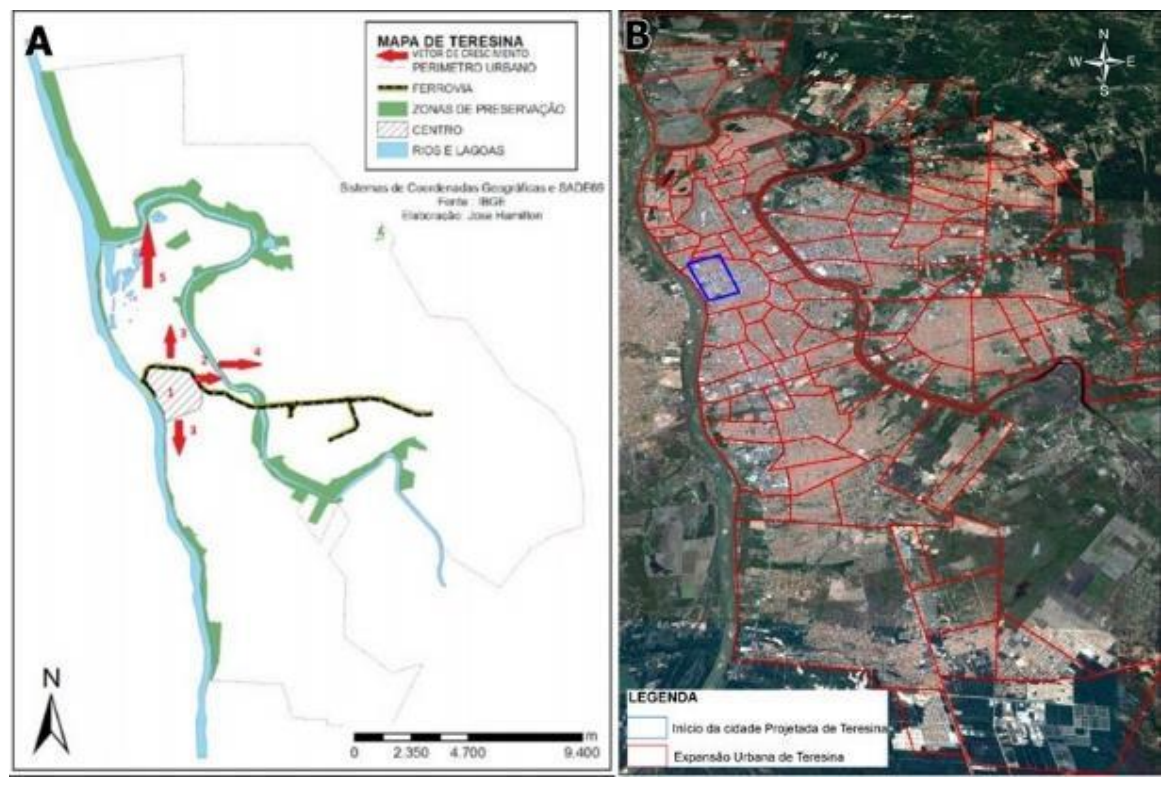

Figura 02. A) Expansão de Teresina a partir do plano inicial; B) Teresina em 2015. Fonte: A) Leal Junior (2014); B) Google Earth (2015). Organizado pelos autores.

Portanto, devido a cidade de Teresina está situada entre rios, para o seu processo de expansão foi necessário a construção de pontes para se chegar as configurações que a cidade tem hoje, como destacou Bueno (2015) as dez pontes existentes hoje na cidade. Então nosso trabalho segue sua análise a partir da Ponte Mestre João Isidoro França, inaugurada em 2010.

\section{MATERIAIS E MÉTODOS}

\subsection{Caracterização da área de estudo}

O trabalho proposto tem como área de análise a Ponte Mestre João Isidoro França (Figura 3A), ponte conhecida mais popularmente como ponte Estaiada ou até mesmo pelo seu antigo nome no começo de sua construção - Sesquicentenário. Localizada na cidade de Teresina no estado do Piauí, cidade com área de 1.391,981 km² e um população 814.230 habitantes (IBGE, 2010).

A Ponte Mestre João Isidoro França foi construída na cidade Teresina, no Piauí, em comemoração aos 150 anos da cidade. Conhecida também como ponte do sesquicentenário, a ponte teve sua construção iniciada em 2002 e foi inaugurada no dia 30 de março de 2010. Com uma 
extensão total de 363 metros, o tabuleiro de concreto protendido possui de cada lado do mastro três faixas de rodagem de 3,1 $\mathrm{m}$ de largura e um passeio de 2,15 $\mathrm{m}$ de largura. $\mathrm{O}$ mastro de concreto possui $98 \mathrm{~m}$ de altura sobre o solo, abrigando no seu topo um mirante em estrutura metálica, que pode ser acessado através de elevadores panorâmicos e escadas de emergência. A execução da ponte teve como finalidade a interligação da Avenida Dom Severino e a Alameda Parnaíba, trazendo melhorias ao trânsito da região. O custo para execução desta ponte, por onde passam 45 mil veículos por dia, foi de 74 milhões de reais (MAZARIM, 2011, p. 109).

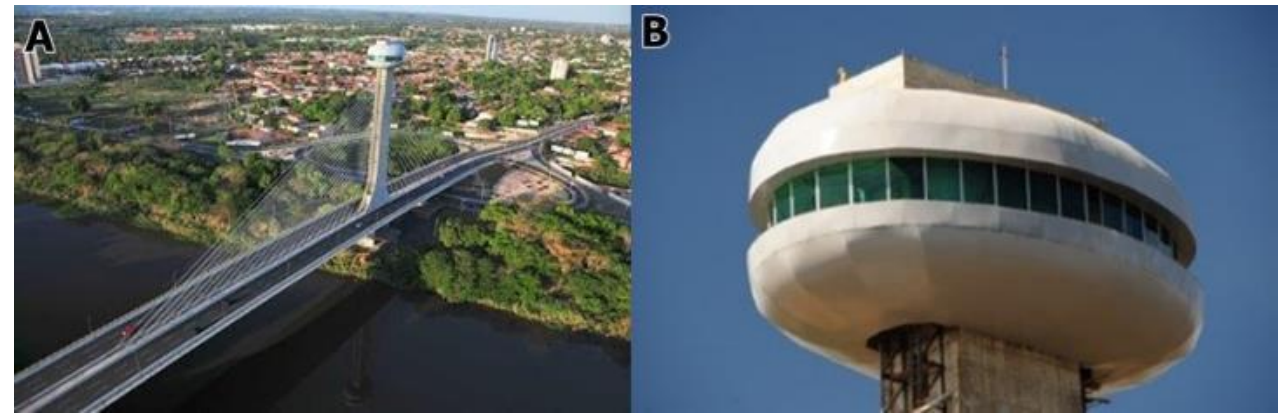

Figura 03. A) Ponte Mestre João Isidoro França; B) Complexo Turístico Mirante Ponte Estaiada. Fonte: A) Mega Engenharia (2012); B) Cidade Verde (2011). Adaptado pelos autores.

O grande destaque desta construção é o seu mirante que se tornou ponto turístico da cidade de Teresina, como pode ser observado na Figura 3B, com o nome de Complexo Turístico Mirante Ponte Estaiada traz o que há de mais moderno no mundo da engenharia e arquitetura para a cidade de Teresina. Sua construção seguiu padrões internacionais de qualidade para oferecer à capital piauiense uma obra que unisse a utilidade pública, beleza, versatilidade e preservação do meio ambiente (TERESINA, 2015).

A área da porção leste da ponte localizada precisamente no bairro de Fátima, localiza-se as principais avenidas da cidade como Avenida Nossa Senhora de Fátima, Avenida Raul Lopes, Avenida Dom Severino e Avenida Homero Castelo Branco. Esta área apresenta grande concentração de renda com $44 \%$ da sua população recebendo mais de dois salários mínimos, segundo dados da Secretaria Municipal de Planejamento e Coordenação - SEMPLAN.

O outro lado da ponte, a região centro/norte da cidade mais precisamente o bairro Morro da Esperança é exatamente o oposto do que se ver na região leste, pois o bairro é conhecido como um lugar perigoso, devido ao intenso tráfico de entorpecentes que acontece na região, onde frequentemente é destaque de notícias policiais da cidade. A renda da população do bairro é baixa, $82 \%$ da população não tem renda ou só recebem um salário mínimo. O valor do rendimento nominal mediano mensal dos domicílios particulares permanentes em 2010 do bairro é de R\$ 1.020,00 abaixo da média da zona Urbana do município de $\mathrm{R} \$ 1.200,00$ e ocupava a $78^{\mathrm{a}}$ no ranking dos bairros. (SEMPLAN, 2015). 
Portanto, a região da entorno da Ponte Estaiada, área a ser analisada em nosso trabalho, traz grande importância para cidade devido ao fluxo de movimentos que existem em sua volta, principalmente por se trata de um ponto turístico da cidade e o grande contraste social existente quando se passa para de um lado para o outro da ponte, e que sofreu ao longo dos últimos anos grandes transformações espaciais.

\subsection{Metodologia}

Para efetivação deste trabalho, utilizamos para nossa análise as imagens de satélites disponibilizados no software Google Earth do entorno da Ponte Estaiada, com um recorte temporal de dez anos. Como pode ser observado na Figura 4A (Jan/2005) e na Figura 4B (Set/2015).

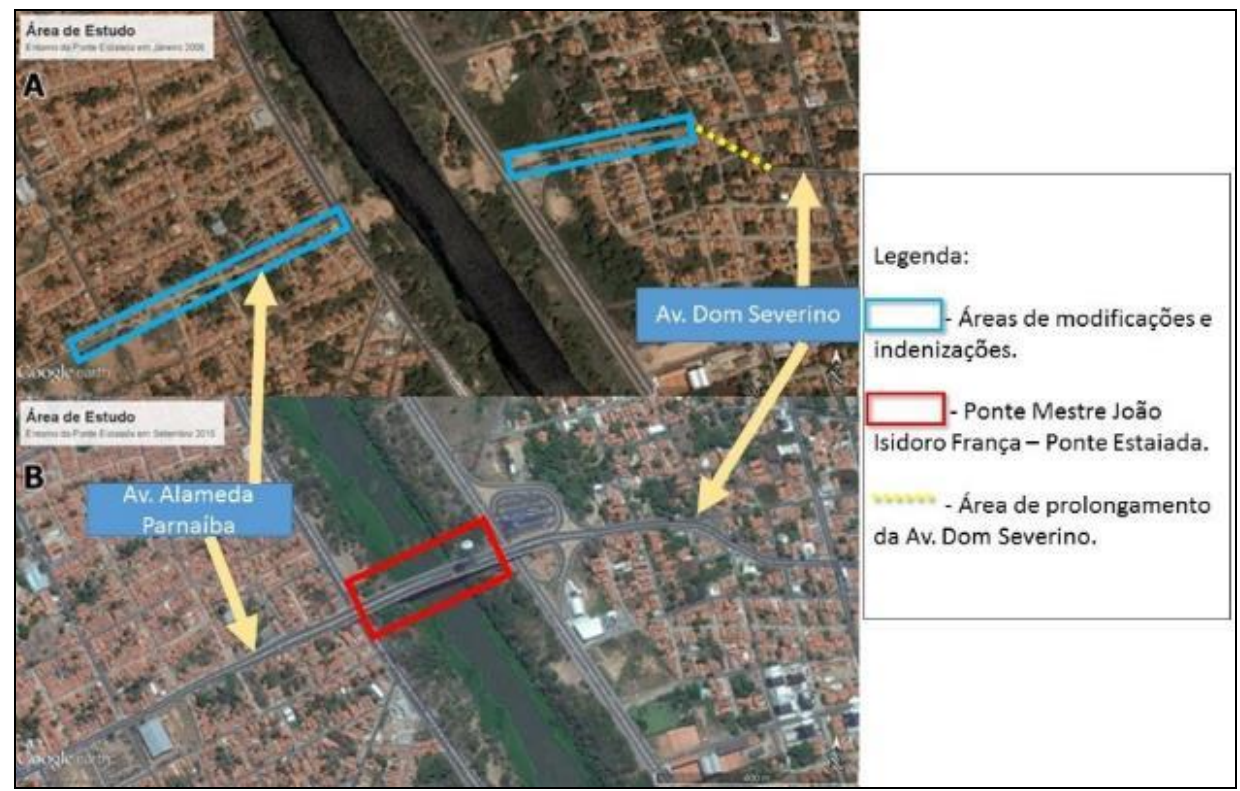

Figura 04. A) Área de Estudo em janeiro/2005; B) Entorno da Ponte em setembro/2015. Fonte: A) Google Earth (2005) B) Google Earth (2015). Organizado pelos autores.

Após a escolha das duas imagens que serviram de base para realização do trabalho foram escolhidos dois pontos para serem analisados e observados suas mudanças ao longo desses dez anos, destacando suas mudanças urbanas na paisagem. A escolha dos dois pontos foi dada em relação ao cotidiano observado no entorno da ponte. O primeiro ponto é o Morro da Esperança por se tratar de um contraste social que existe entre os dois lados da ponte e o segundo ponto para nossa análise é o prolongamento da Avenida Dom Severino para dá a acesso a ponte.

Além das escolhas das imagens base e dos pontos, foram realizados procedimentos de campo para retirada das fotografias nos pontos escolhidos, análise bibliografia referente ao tema e área da ponte em artigos científicos, busca na internet em sites de noticiários e organizações públicas para informações a respeito da construção da ponte. E por fim que serão analisados os dois pontos em destaque, mostrando como foi deste processo de modificação da paisagem urbana. 


\section{RESULTADOS E DISCUSSÃO}

O primeiro ponto analisado foi o Morro da Esperança, considerada uma área marginalizada da cidade, por estar situada na periferia da mesma. O maior problema enfrentado nessa área foi desocupação das propriedades privadas para as construções das alças acesso a ponte, como retrata o portal 180 graus em artigo publicado em seu site no dia 09/10/2009 "Situações como essa mostram até que ponto o progresso interfere na vida da população, especialmente, quando ela é de baixa renda.". Segundo mesmo artigo o problema do Morro da Esperança em questões das indenizações foi que muitos dos populares ficaram insatisfeitos pelos valores oferecidos a suas propriedades pela Prefeitura, as mesmas foram avaliadas pela Prefeitura apenas pelo que existia no terreno e muitos deles não tinham documentação.

Outro ponto destacado pelos populares era que o valor da indenização não seria suficiente para comprar outra propriedade na mesma região e também a questão de afinidade com a região por ter habitado na área por mais de 30 anos. A solução proposta pela a Prefeitura foi o deslocamento das famílias para o conjunto habitacional Leonel Brizola, no bairro Monte Verde, e muitos moradores recusaram devido a distância do local oferecido. O que ganhou destaque nessa disputada entre Prefeitura e moradores do Morro da Esperança é que as indenizações do outro lado da ponte, zona leste da cidade, eram muito maiores e a explicação da Prefeitura foi que os terrenos da zona leste eram maiores e tinham documentação. O saldo final dessa disputa foi 131 casas desapropriadas na zona centro/norte e 26 na zona leste, e todas avaliadas pela Caixa Econômica Federal. Pode-se observar na Figura 5A e 5B as mudanças na paisagem do local.
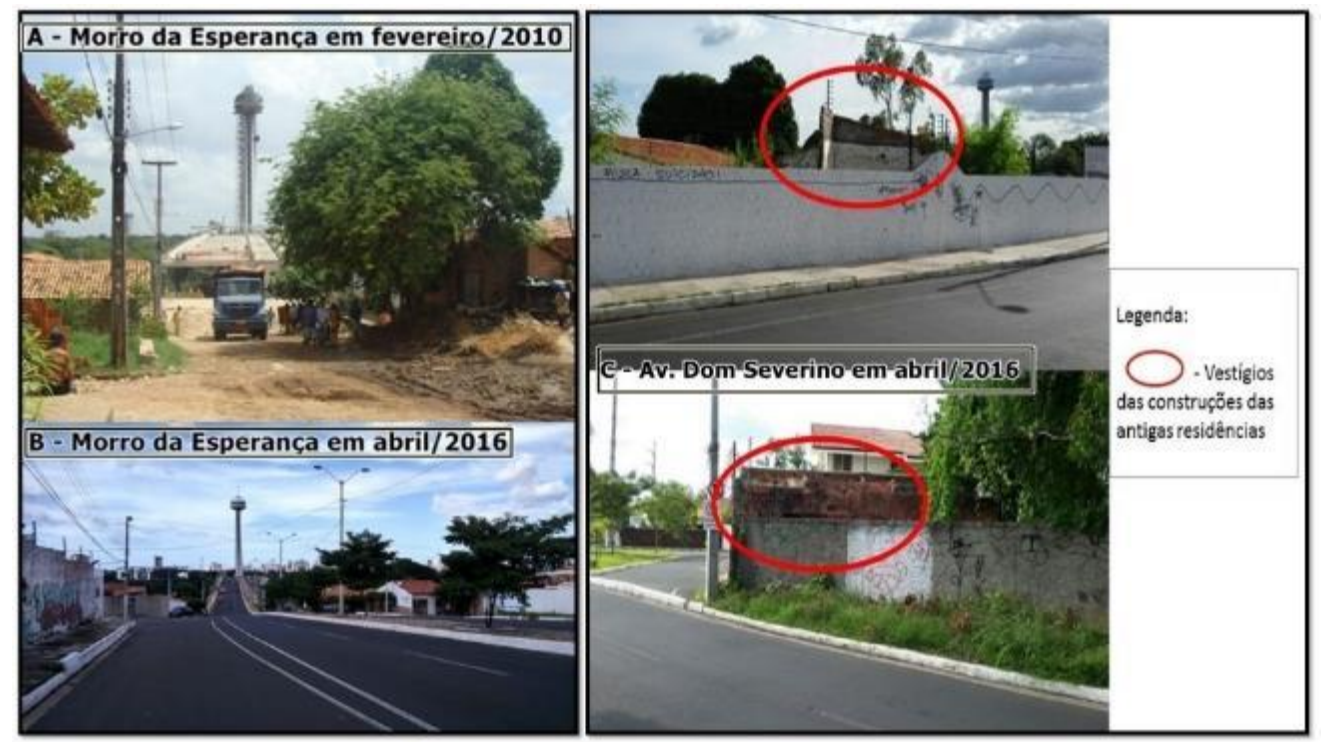

Figura 05. A) Morro da Esperança em fevereiro/2010; B) Morro da Esperança em abril/2016; C) Av. Dom Severino em abril/2016. Fonte: A) Cidade Verde (2010); B) e C) Autores (2016). Organizado pelos autores. 
O segundo ponto a ser analisado corresponde ao prolongamento da Avenida Dom Severino para o acesso a ponte. Este ponto foi destaque devido as polêmicas pelo fato de ter que ser demolida algumas residências para que a avenida fosse prolongada e o problema ainda provocou mais questionamentos, pelas grandes diferenças nos valores das indenizações aos proprietários das residências demolidas nas duas margens do rio, sendo as da zona centro/norte com menor valor, devido se encontrarem em um bairro de menor poder aquisitivo e as residências da zona leste possuir uma infraestrutura bem melhor e por se localizarem na zona nobre, possuir um valor de indenização bem maior. Isso condiz com o que Aragão e Mendes (2015) afirmar que a demora da obra ocorreu devido a zona leste ser formada por uma população de poder aquisitivo alto e que dificultou a negociação para a desapropriação dos terrenos que possibilitasse os terrenos para a execução das vias de ligação para a ponte.

Como a Figura 5A mostra que, antes da construção da ponte, a ocupação do espaço urbano ocorreu de forma desordenada, sem o devido planejamento urbano, daí ocorreram as indenizações e desocupações das residências para que a ponte pudesse ser concluída (Figura 5B). Observa-se que a Avenida Dom Severino finaliza em uma residência, pelo fato da ocupação desse espaço não seguir um planejamento urbano, na verdade ocorreu de forma aleatória. Isto vai ao encontro do que Aragão e Mendes (2015) afirma que a ocupação posterior da zona leste aconteceu irregularmente, sem um plano regulador único que criasse um padrão, ao contrário, o crescimento ocorreu desordenado, criando uma diversidade do espaço urbano, com lotes de dimensões distintas e sem uma definição da localização dos demais usos para o bairro.

Sendo mais viável o acesso à Ponte pela Av. Dom Severino, em virtude da infraestrutura já existente na mesma, foi necessário a demolição das residências que se encontravam no trajeto do prolongamento, havendo, portanto, a indenização dos proprietários dos imóveis. Na Figura 5C é possível perceber os vestígios das construções das antigas residências que faziam parte de uma arquitetura urbana, que ficará presente apenas na memória das pessoas que viveram nesse local.

\section{CONSIDERAÇÕES FINAIS}

Constatou-se que o espaço urbano está em constante mudança, seja ele planejado ou não. Analisando as duas imagens como bases, em um recorte temporal de dez anos, oferecida pelo software Google Earth, observamos facilmente mudança da área entorno da Ponte Estaiada no decorrer deste tempo sem ir muito longe, apenas através das observações das imagens.

Nessa perspectiva mais uma vez vale ressaltar a importância da aplicação do planejamento urbano no processo de ocupação e estruturação do espaço urbano, pois os projetos não trabalham somente com a situação do momento, mas com perspectivas de futuro, obviamente construindo 
infraestruturas urbanas adaptáveis a possíveis modificações futuras. No caso do Morro da Esperança e do prolongamento da Avenida Dom Severino, se a ocupação desses espaços tivesse sido promovida por um plano diretor, provavelmente essas ocupações aleatórias não teriam ocorrido e seus espaços para expansão urbana teriam sido preservados, para um caso de necessidade de ampliação da via no futuro, como de fato foi necessário, reduzindo inclusive o custo da obra aos cofres públicos.

\section{REFERÊNCIAS}

180 GRAUS. Ponte do Sesquicentenário: Há denúncia de ameaça. Disponível em $<$ http://180graus.com/politica/ponte-do-sesquicentenario-ha-denuncia-de-ameaca-249347.html>. Acesso em 08 jun. 2016.

ABREU, Irlane G. de; LIMA, Iracilde Maria de M. F. Igreja do Amparo: o marco zero de Teresina. Cadernos de Teresina. Ano XII, n. 33, out., p. 20-25, 2000.

ARAGÃO, Juliana Lopes; MENDES, Hercília Raquel de Sousa. Memória urbana da avenida Dom Severino: análise das edificações. Pós. Revista do Programa de Pós-Graduação em Arquitetura e Urbanismo da FAUUSP, São Paulo, v. 22, n. 38, p. 78-93, dez. 2015. ISSN 2317-2762. Disponível em: <http://www.revistas.usp.br/posfau/article/view/112362>. Acesso em: 25 julho 2016.

BUENO, P. H. C.; LIMA, A. J. (RE) Estruturação urbana de Teresina (PI): uma análise de suas dinâmicas recentes. In: XIV Simpósio Nacional de Geografia Urbana-SIMPURB, 2015, Fortaleza. Anais. XIV Simpurb, 2015. v. 1.

CASTELO BRANCO, Antônio Frederico Vilarinho. A ação do Estado e do mercado imobiliário no processo de segregação sócio espacial em bairros na zona leste de Teresina. 2012. $168 \mathrm{f}$. Tese (doutorado) - Universidade Estadual Paulista, Instituto de Geociências e Ciências Exatas, 2012. Disponível em: 〈http://hdl.handle.net/11449/104424>. Acesso em 2 abr. 2016.

CIDADE VERDE. Ponte do Sesquicentenário no Piauí é semelhante à de SP. Disponível em <http://cidadeverde.com/noticias/32561/ponte-do-sesquicentenario-no-piaui-e-semelhante-a-de-sp>. Acesso em 08 jun. 2016.

FAÇANHA, Antônio Cardoso. A Evolução Urbana de Teresina: Agentes, Processos e Formas Espaciais da Cidade. 1998. 233f. Dissertação (Mestrado em Geografia). Universidade Federal de Pernambuco, Recife, 1998.

INSTITUTO BRASILEIRO DE GEOGRAFIA E ESTATÍSTICA. Cidades. Disponível em <http://cidades.ibge.gov.br/xtras/perfil.php?codmun=221100>. Acesso em 08 jun. 2016.

LEAL JUNIOR, José Hamilton. Expansão Urbana, planos urbanísticos e segregação urbana: O caso de Teresina-PI / José Hamilton LEAL JUNIOR; orientador, Ayrton Portilho Bueno - Florianópolis, SC, 2014. 144p. Dissertação (Mestrado) - Universidade Federal de Santa Catarina, Centro Tecnológico. Programa de Pós-Graduação em Arquitetura e Urbanismo.

LIMA, I. M de M. F. Teresina: Urbanização e Meio Ambiente. In: Scientia et Spes: Revista do Instituto Camilo Filho, Teresina: v.1, n.2, (2002), Cap. 09, p.181 -206, 2002. ISSN 1676-3815.

MAZARIM, Diego Montagnini. Histórico das pontes estaiadas e sua aplicação no Brasil / D.M. Mazarim. - Ed.rev. - São Paula, 2011. 125p. Dissertação (Mestrado) - Escola Politécnica da Universidade de São Paulo. Departamento de Engenharia de Estruturas e Geotécnicas.

MEGA ENGENHARIA. Ponte Estaiada de Teresina. Disponível em <http://megaengenharia.blogspot.com.br/2012/08/ponte-estaiada-de-teresina.html >. Acesso em 08 jun. 2016. TERESINA. Complexo turístico mirante ponte estaiada. Disponível em <http://www.teresina.pi.gov.br/sistemas/sitioprodater/download/5536c8a3a9.pdf>.Acesso em 08 jun. 2016. . SEMPLAN. Teresina - Perfil dos Bairros. Disponível em <http://semplan.teresina.pi.gov.br/wpcontent/uploads/2014/09/F\%C3\%81TIMA.pdf>. Acesso em 08 jun. 2016.

SEMPLAN. Teresina - Perfil dos Bairros. Disponível em<http://semplan.teresina.pi.gov.br/wpcontent/uploads/2014/09/MORRO-DA-ESPERAN\%C3\%87A-2015.pdf>. Acesso em 08 jun. 2016. 
TERESINA ANTIGA. Antigas chácaras e quintas de Teresina. Disponível em<http://teresinaantiga.com/antigas-chacaras-e-quintas-de-teresina.php>. Acesso em 08 jun. 2016.

TOLLSTADIUS, Larissa Lira. Preservação do Centro de Teresina: a construção de um objeto / Larissa Lira Tollstadius - Instituto do Patrimônio Histórico e Artístico Nacional, 2013. 135 f.: il. Dissertação (Mestrado) - Instituto do Patrimônio Histórico e Artístico Nacional, Mestrado Profissional em Preservação do Patrimônio Cultural, Rio de Janeiro, 2013.

VIANA, B. O sentido da Cidade: Entre a Evolução Urbana e o Processo de Verticalização. Carta Cepro. V.23, n.1, 2005.

Recebido em: 14/08/2016

Aceito para publicação em: 01/10/2016 